\title{
Lipid Metabolism Reprograming as a Target for Cancer
}

\author{
Yan Xu* \\ Department of Obstetrics and Gynecology, Indiana University School of Medicine, 950 W. Walnut St. R2-E380, Indianapolis, IN 46202, USA
}

\begin{abstract}
Targeting metabolic reprograming has emerged as an exciting area in cancer research. Lipids, and fatty acids and cholesterol in particular, have generally been considered to possess tumor promoting activities and have been targeted for cancer treatment in in vitro and in vivo studies, including clinical trials. Low fat diet has been accepted by the public as it is associated with human health. However, large body of evidence indicates the lack of scientific consensus in these areas. Updated contradictory data are presented in this paper with potential interpretations, which may significantly affect public diet selections and clinical practice in this area. Much greater efforts are needed in the area of nutrition research, in metabolic reprograming, and in lipid metabolism pertinent to cancer. These studies are pivotal to provide critical information for cancer prevention, detection, prognosis, and treatment.
\end{abstract}

\section{Introduction}

Advances in DNA and RNA sequencing over the past decade have made it possible to systematically study genetic, as well as epigenetic changes related to altered gene expression levels in cancer $[1,2]$. In particular, the Pan-Cancer Atlas analyses have been conducted based on The Cancer Genome Atlas (TCGA) data of over 11,000 tumors from 33 of the most prevalent forms of cancer, using comprehensive, in-depth, and interconnected bioinformatics analyses. This large-scale collaboration initiated and supported by the National Cancer Institute (NCI) and National Human Genome Research Institute (NHGRI), has resulted 27 high-impact papers divided into three main categories: cell-of-origin patterns, oncogenic processes, and signaling pathways. In its comprehensive analysis of tumor signaling pathways, metabolic pathways analysis is one of the major focuses $[3,4]$.

Degeneration of cellular energetics, or metabolic reprograming in general, is one of the important cancer hallmarks [5]. Since the "Warburg effect" and the fatty acid de novo synthesis hypotheses proposed in 1920s [6] and 1950s [7], respectively, cancer cell metabolism reprograming has emerged as a major area of research and new targets for cancer diagnosis, prognosis, and/or therapy in recent years $[8,9]$. However, low efficacy and/or controversial outcomes exist in targeting metabolism reprograming in pre-clinical or clinical trials [10-12]. Practical and high clinical efficacy targeting of metabolism reprograming in cancer is yet to be developed. More in-depth tumor metabolic studies and analyses are critical to provide the pivotal bases for this development.

In this review paper, lipid reprograming and their potential clinical implications in cancer will be the focus. The current controversies in this field will be discussed with perspectives.

\section{Lipid Metabolism Reprograming as a Target for Cancer}

\section{Up- or down regulation of lipid synthesis in cancer cells?}

Our recent bioinformatics analyses of the RNA-seq data from a syngeneic epithelial ovarian cancer (EOC) cell pair, representing more and less aggressive tumor cells in vivo have identified an unexpected major down-regulated pathways in the more aggressive EOC cells are related to lipid metabolism, mainly to cholesterol, steroid hormone, and fatty acid metabolisms [13]. The two key enzymes involved in cholesterol and fatty acid synthesis, HMG-CoA reductase (Hmgcr in mouse and HMGDR in human), and fatty acid synthase (Fasn in mouse and FASN in human) were both down regulated in more aggress vs. less-aggressive EOC cells [13]. On the other hand, several enzymes in fatty acid $\beta$-oxidation, including the rate limiting enzyme carnitine palmitoyltransferase 1 (Cpt1), hydroxyacyl-CoA dehydrogenases (Hadha and Hadhb), and acetyl-CoA acyltransferase 2 (Acaa2) are upregulated 1.3 to 3.7 folds ( $\mathrm{P}$ values $<3 \times 10^{-4}$ ) in more aggressive EOC cells [13].

This is unexpected, since up-regulation of lipids, including cholesterol and fatty acids, have been shown to be associated with cancer and they play tumor-promoting roles in many cancers, including EOC [14-16]. Inhibitors targeting the rate-limiting enzymes in cholesterol and fatty acid synthesis, such as statins and FASN inhibitors have been used in the management of several cancers [11,17-19].

However, our findings are highly consistent with the PanCancer Atlas analyses [3], in which Peng, et al. have characterized the molecular features and clinical relevance of metabolic expression subtypes in human cancers, using molecular data of 9,125 patient samples from TCGA [3]. Interestingly, while upregulated metabolism of carbohydrate, nucleotide, and vitamin \& cofactor are associated with poor prognosis, upregulated TCA cycle and lipid metabolic subtypes are associated with better prognoses [3].

\section{The role of fatty acids and cholesterols in cancers}

The potential tumor-promoting roles of lipids (mainly fatty acids and cholesterols): Many publications have demonstrated the

*Correspondence to: $Y$ an Xu, Department of Obstetrics and Gynecology, Indiana University School of Medicine, 950 W. Walnut St. R2-E380, Indianapolis, IN 46202, USA, Tel: (317) 274-3972; E-mail: xu2@iupui.edu

Key words: cholesterol, Epithelial ovarian cancer (EOC), fatty acid, lipid metabolism, The Pan-Cancer Atlas, The Cancer Genome Atlas (TCGA)

Received: August 21, 2019; Accepted: August 27, 2019; Published: September 02,2019 
tumor promoting activities of fatty acids and/or cholesterols [1416, 20-22]. Activated lipid synthesis has been shown to be essential for cancer cells. Lipids are not only the main components of plasma membranes, but also function as energy source, signaling molecules, and posttranslational modifiers for proteins [23].

A significant portion of the studies supporting targeting fatty acid and cholesterol synthesis in cancer is from epidemiologic data linking diabetes, obesity, and/or diet to cancer [20-22]. In particular, adipose tissue plays important roles in providing energy, regulating glucose and lipid metabolism, and modify the immune system in cancer microenvironment $[20,24,25]$.

Lipids in high fat diets (HFD) increase oncogenic KRAS activity and stimulate proliferation of pancreatic cancer cells lines [18]. External cholesterol can directly activate the oncogenic Hedgehog pathway, and internal cholesterol can induce mTORC1 signaling [26]. Fat and specific fatty acids up-regulate inflammatory mediators in human and animal studies. High-fat diets may also promote unfavourable epigenetic profiles [27].

FASN and HMGCD are the rate-limiting enzymes for fatty acid and cholesterol de novo synthesis, respectively (Figure 1). Fatty acid synthesis enzymes, and FASN in particular, are often over-expressed in cancer [28-30]. Cholesterol is mainly synthesized by the liver in the body, but all types of cells are able of cholesterol synthesis [31]. Cholesterol biosynthesis has been reported to be elevated in proliferating normal tissues and tumor cells [31,32].

In hepatocellular carcinoma cells, silencing of FASN significantly decreases cell proliferation [33]. Che, et al. have examined the role of FASN in hepatocarcinogenesis and found that while overexpression of FASN is insufficient in induction of transformation of hepatocytes, it plays a necessary role in AKT and AKT/c-Met proto-oncogene-driving hepatocarcinogenesis in mice [34]. FASN knockdown in endothelial cells impedes vessel sprouting by reducing proliferation [35]. In ovarian cancer models, FASN has been shown to be involved in cell migration, tumor development, and metastasis in vitro or in vivo [36].

FASN has been considered as an attractive target for therapeutic intervention. Many FASN inhibitors have been developed and at least one of them has successfully advanced through the drug development process and entered clinical evaluation in oncology [37-39]. Blockade of FASN using inhibitors induces degradation of phosphoinositide3-kinase signaling proteins, apoptosis, cell death, and reduced tumor growth in ovarian cancer [40-42].

Statins targeting HMGCR are well-known cholesterol-depleting agents and have been tested since the early 1990s [38,43]. Certain clinical benefits have been reported in specific cancers [44-49] when statins were used as a single reagent or in combination with a chemotherapy or a different reagent.

The controversial roles of fatty acid and cholesterols in cancer: For decades, there is a public consensus that high intakes of fat cause obesity, diabetes, heart disease, and cancer [27]. However, Ludwig, et al. have recently presented accumulated data showing that no-effect or opposite correlations among high-fat diets and cancer incidence, recurrence, and/or mortality. In addition, they have summarized existing evidence to support that the pleiotropic anti-diabetic and anti-inflammation effects of low-carbohydrate, high-fat diets [27]. Moreover, the authors emphasis the different roles of different fatty acids, with trans and saturated fat positively, and unsaturated fat negatively correlated to mortality [27].

The prognostic value of serum lipid markers in cancer is debatable issue. For example, a recent meta-analysis of data from 26 studies including 24,655 individuals revealed that serum blood total cholesterol

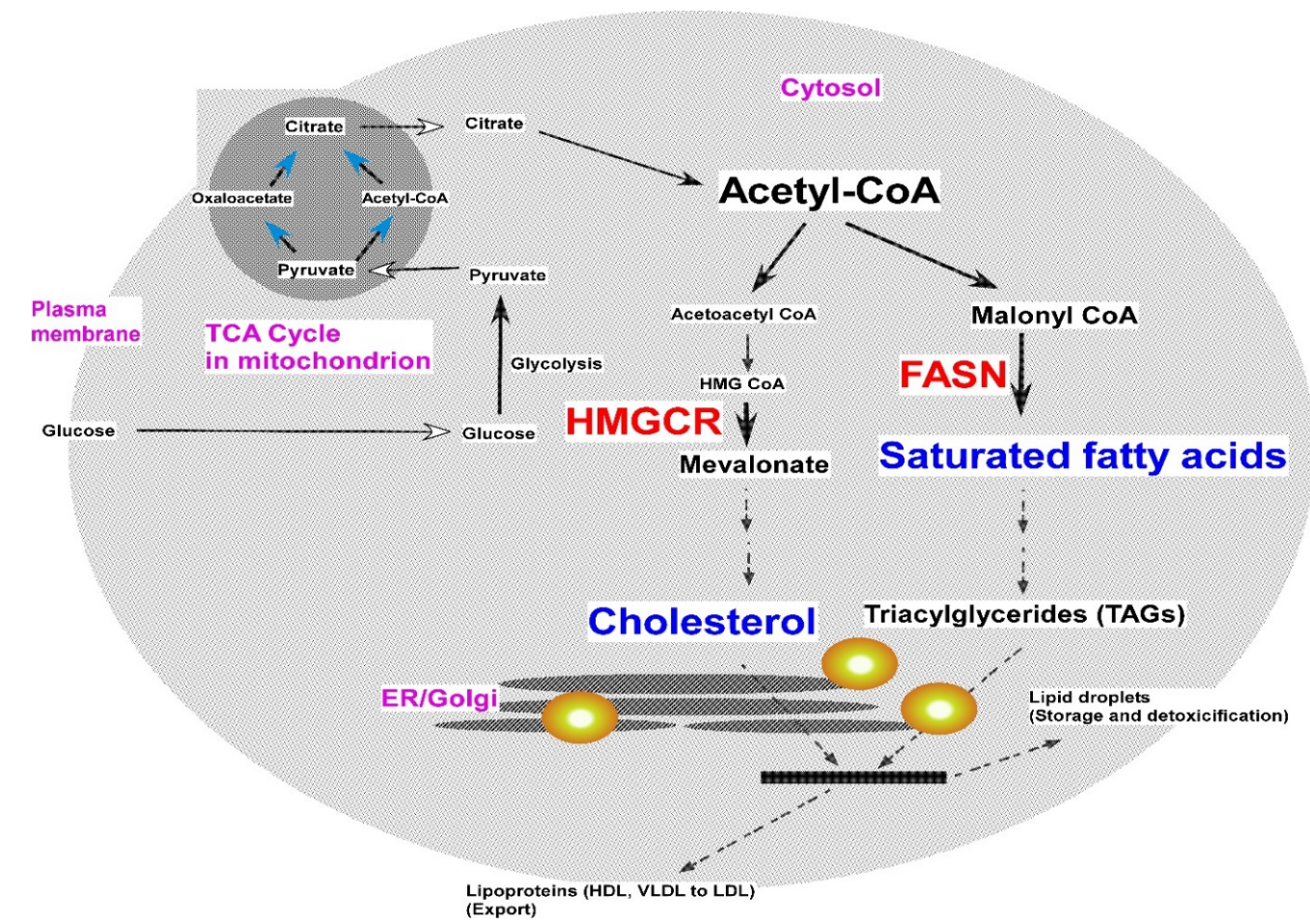

Figure 1. Fatty acid and cholesterol synthesis in cells: HMGCR and FASN are rate limiting enzymes in cholesterol and fatty acid synthesis, respectively. ER=Endoplasmic reticulum 
(TC) and low-density lipoprotein cholesterol (LDL-C) are actuarially a protective factor for overall survival in cancer patients [50]. In another systematic review and meta-analysis, Hao, et al. have concluded that high serum HDL-C levels are associated with better overall survival and disease-free survival in patients with solid tumors [51]. LDL, on the other hand, may have opposite functions in breast and other cancers [52]. Moreover, cholesterol, cholesterol derivatives, and their transporters add more complexity in the spectrum [53-55].

While Braicu, et al. have reported overall reduction of most lipid classes in the serum of high-grade serous ovarian cancer (HGSOC) patients, they emphasized that elevation of individual specific lipids, including ceramide and triacylglycerol (TAG) lipid species are noted [56]. The reduction of overall lipids may be related to lipotoxicity, which is related to increased lipid droplets in cancer cells to sequester toxic lipids, including fatty acids, cholesterol, and ceramides [57], reflecting one of the adaptabilities of cancer cells.

Statins are one group of "redirected" drugs. They are originally been used for the treatment of hypercholesterolemia and cardiovascular diseases by inhibiting HMGCR. Due to the potential linkage of hypercholesterolemia and cancer, they have been redirected to cancer treatment $[11,17]$. However, their efficacy and benefit toward cancer is rather controversial, ranging from beneficial effect, no effect, to even negative effect. For example, statin intake has been shown to be insignificantly associated with prognostic factors of prostate cancer or increase invasive breast disease $[11,58,59]$. In a clinical study, a significant higher portion of patients with bladder cancer became more aggressive who took statins than those nonusers [10]. Overall, despite numerous studies, there is still considerable debate on whether statins are useful in cancer treatment and prospective clinical studies have mostly not been successful [60]. A recent systematic review and meta-analysis of randomized controlled trials on statin therapy in the treatment of active cancer has been conducted [61]. The data have shown that the overall survival or progression-free survival of patients with advanced cancer with a prognosis $<2$ years is not significantly improved by adding statins to standard anti-cancer therapy [61]. These data clearly emphasis that it is still immature to draw a definitive conclusion for the usage of statins in cancer treatment based on the current available information.

Preclinical studies in mice using FASN inhibitors have demonstrated their anti-tumor activity in several cancers, including pancreatic, colorectal, and ovarian cancers $[19,62]$. However, no tumor response is reported in one clinical trial using a FASN inhibitor. Off-target effect has been considered as one of the potential reasons, as orlista has at least seven known targets [28]. Other clinical trials using TVB-2640, a FDA-approved FASN inhibitor, for advanced breast cancer, relapsed high-grade astrocytoma, colon and other cancers are ongoing.

\section{The potential interpretations for the discrepancy in the role of lipid metabolism reprograming in cancer}

Expression vs. function: Although lipogenic enzymes have been shown to be frequently overexpressed in many cancer types $[18,63]$, the Pan-cancer Atlas analyses conducted based on $>9,000$ tumors revealed an association between with upregulated lipid metabolism and better prognosis [3], indicating the importance of investigating correlative data in the functional/clinical outcome context. This is supported by our RNAseq data that are generated from a pair of syngeneic cell lines with dramatic differences in tumor formation function $[13,64,65]$, which also suggest that our data, although it derived from mouse EOC cell lines, are in line with large scale human TCGA data from 33 tumor types.
In vitro vs. in vivo: Functional studies to elucidate the roles of fatty acids and cholesterol in cancer have actually been conducted in many of the previous studies in both in vitro and in vivo mouse model studies. Genetic modification of genes encoding lipogenic enzymes and applications of specific inhibitors linking to functional assays have been tested to show that these enzymes are functionally involved in tumor promoting in various cancer types $[18,26,63]$.

However, some of these studies may be limited by certain conditions, which do not fully recapitulate human cancer pathologically, including 2D vs. 3D cell cultural conditions; cells in attachment $v s$. in suspension (to be discussed in detail in below); and the lack of the tumor microenvironment influence in in vitro studies. As an example, mouse ID8 EOC cells were original established through spontaneous transformation of normal ovarian surface epithelial cells [66]. Once transformed, however, numerous in vivo passages of ID8 cells do not further enhance their tumorigenic aggressiveness, accessed by their tumor/ascites formation time being consistently $\sim 90$ days ([66-68] and our unpublished data from more than 100 mice tested). On the contrary, only one-time in vivo passage has dramatically increased their aggressiveness as we reported previously [65]. These data indicate that the tumor microenvironment (TME) plays pivotal regulatory roles in cancer cells. It is worthwhile to note that studies conducted in mice may not fully recapitulate human cancer pathology, but the mouse models are still highly valuable for pre-clinical studies.

Cells in attachment $v s$. in suspension; 2D vs. 3D cell culture: Adenocarcinomas are derived from epithelial cells, which are attached to the basal layer in normal physiology. When cancer cells grow and metastasize, they need to detach, migrate, and invade. During metastasis, cancer cells need to survive in suspension conditions and often encounter highly stressful microenvironment, including immune attacks, nutritional alterations, and hypoxic conditions. The floating circulating tumor cells (CTCs) have been considered as tumor markers $[69,70]$. For EOC, the floating cells are particularly relevant. Most last stage EOC patients develop ascites in the peritoneal cavity, with large numbers of floating tumor cells, tumor-interacting host cells, as well as many soluble growth factors, cytokines, and bioactive lipid factors present. Malignant ascites presents an active and rather unique TME for EOC, which is also a home for cancer stem cells. Hence, it provides a wealth of opportunities for translational research [71,72], including developing tumor markers and therapeutics. The limitations of cells cultured in 2D cell culture dishes have now been well recognized. Many $3 \mathrm{D}$ and organoid systems for cancer cells derived from different tissues have been developed in recent years [73,74].

We have found that while ID8-P1 (in vivo passage 1) possesses dramatically increased tumor aggressiveness (assessed by tumor/ ascites formation time), they do not gain a proliferation advantage $v s$. ID8-P0 cells, when they are cultured in vitro using $2 \mathrm{D}$ attachment cell culture plates, but they survived better in suspension and displayed increased ( $\sim 3$-fold) colony formation capacity in 3D culture [65]. More interestingly, the increased aggressiveness of ID8-P1 cells in vivo is directly related to early-stage tumor cells survival in the peritoneal cavity, which is likely a rate-limiting and critical step for tumor development [65]. Intriguingly, dramatically increase in triacylglycerols (TAG; 3.28.6 fold) was observed when EOC cells were cultured in suspension $v$. in attachment [75]. It would be interesting to test whether TAG increase is a general phenotype for detached cancer cells and hence represents a target of these relative vulnerable cells. These data emphasize the importance of experimental conditions in data interpretation. 
Where to target fatty acid and cholesterol metabolism: Many of the studies supporting the tumor promoting roles of fatty acid and cholesterol are based on diet and externally administered lipids as mentioned above. A significant portion or even the majority of TME lipids, and cholesterol in particular, are produced by non-tumor cells, and may not be related to tumor cell lipid metabolisms. Normal cells in the liver and the brain are the main sources for the circulating cholesterol. Compared to other normal cells in other tissues, tumor cells may have altered lipid metabolism at multiple levels, by influencing de novo synthesis, uptake, or efflux pathways of cholesterol [76]. However, many of the published studies did not systematically study these differential roles and/or regulations, which may exert complex roles in tumor progression and/or patients' prognoses. Systemically administrated statins are likely to affect both physiological and pathological lipid synthesis in host and tumor cells, which may exhibit differential and even opposing effects in overall tumor progression. More specific targeting of TME and/or systemic lipid metabolism warrants further investigation.

Different and opposing roles of different lipid species: Fatty acids are a group of compounds, varying in their carbon chain length in general from 14 to 22; number and position of double bonds from one to six, and whether the double bonds are in cis or trans configuration. Cholesterol is a precursor for sex hormones and vitamin $\mathrm{D}$, and there are several other cholesterol derivatives. As mentioned above, different fatty acids have profoundly different effects on mortality [27].
Cholesterol associate with LDL and HDL, or cholesterol derivatives are likely to have distinct and/or opposing effects [51-55,77]. Overall inhibition of fatty acid and/or cholesterol synthesis may thus induced complex outcomes.

In fact, even the roles of unsaturated fatty acids in cancer are highly controversial, with beneficial, no effect, or even detrimental (increased cancer incidence) effects reported \{[78-80] ("Omega-3 Fatty Acids - Health Professional Fact Sheet"). US National Institutes of Health, Office of Dietary Supplements. 2 November 2016) [78-80]\}. In fact, a largest-ever vitamin D and omega-3 trial (VITAL), a $2 \times 2$ factorial randomized, double-blind, placebo-controlled trial has concluded that there is no significant difference in incidence of major cardiovascular events or cancer in the omega-3 fatty acid supplemented vs, the placebo group (Funded by the National Institutes of Health and others; VITAL ClinicalTrials.gov number, NCT01169259) [81].

Omega -3 fatty acids ( $\omega-3, \omega-6$ and $\omega-9$ FAs) contain 1 to 6 double bonds (Figure 2). Both omega- 3 and omega- 6 fatty acids are essential fatty acids, since humans and other animals cannot synthesize them, but they are essential for body and cellular functions [82].

The three most common and dietary types of omega -3 fatty acids involved are $\alpha$-linolenic acid (ALA), eicosapentaenoic acid (EPA) and docosahexaenoic acid (DHA) ("Essential Fatty Acids". Micronutrient Information Center, Oregon State University, Corvallis, OR. May 2014 Retrieved 24 May 2017.). Arachidonic acid is a very important omega-6
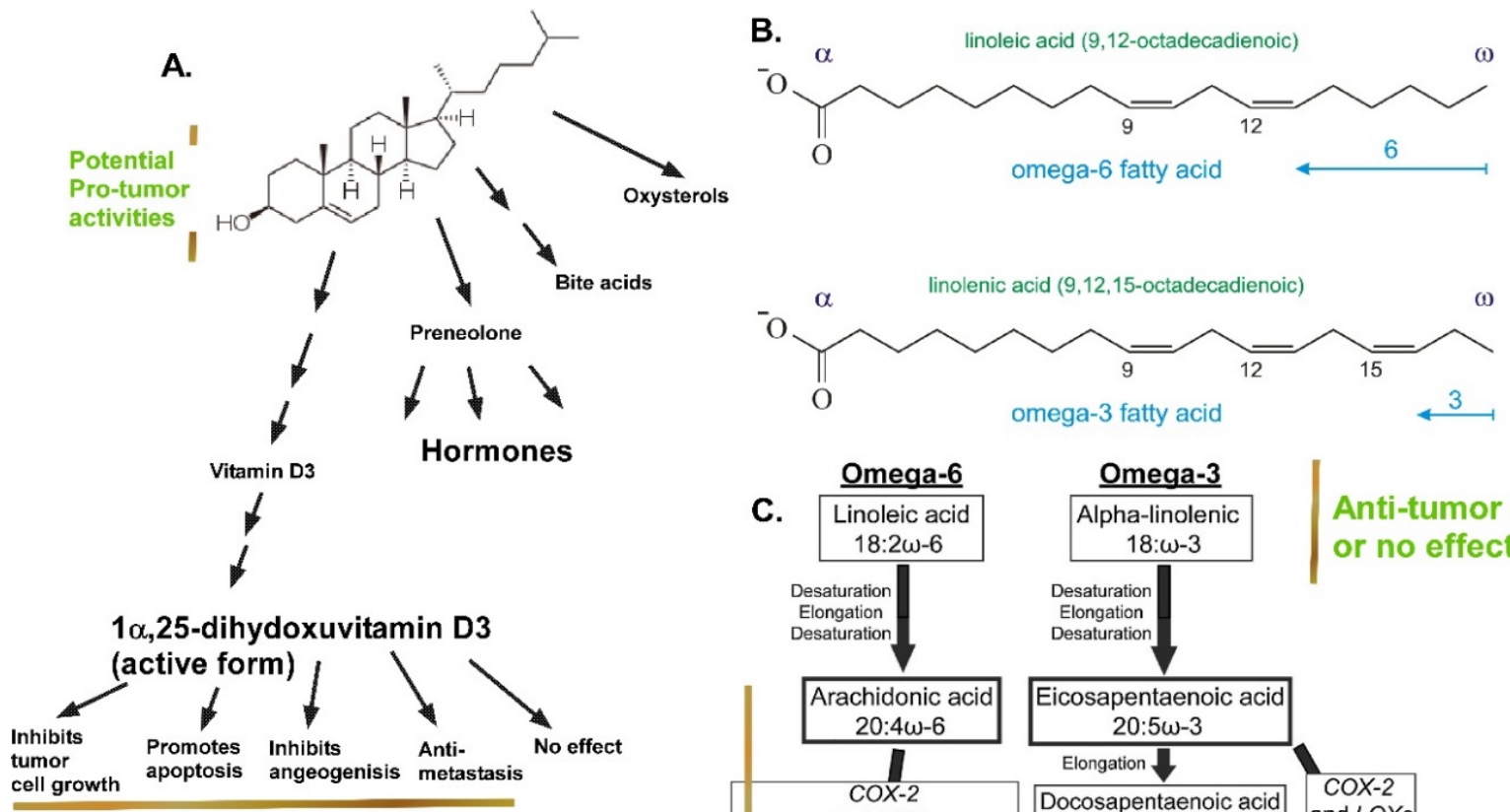

The potential anti-tumor effects of vitamin D3<smiles>C=C1/C(=C\C=C2/CCCC3(C)C2CCC3C(C)CCCC(C)(C)O)CC(O)C[C@@H]1O</smiles>
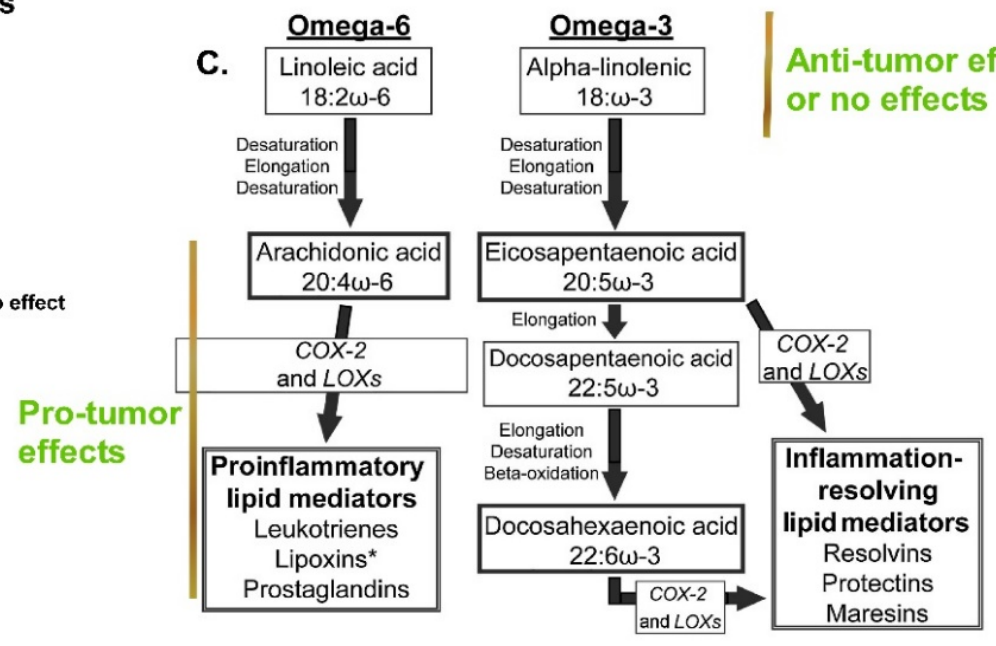

Anti-tumor effects or no effects

C. $18: 2 \omega-6$

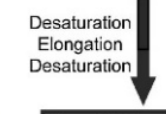

Figure 2. The structures and functions of cholesterol and fatty acid, as well as their derivative in cancer: The complex tumor-related effects of cholesterol and its derivatives (A), and fatty acids (B and $\mathbf{C}$ ) and their derivatives. Saturated fatty acids do not contain double bonds in the backbone (not shown). Omega-3. Omega-6, and their derivatives may have tumor-promoting, tumor-suppressing, or have no effects, as detailed in Section-Different and opposing roles of different lipid species. Part of the figure was from E. Generalic, https://glossary.periodni.com/ glossary.php?en=omega-3+fatty+acids (Permission is granted to copy, distribute and/or modify this image freely for any purpose, including commercial use, as long as the author and the source are credited: E. Generalic, https://glossary.periodni.com/glossary.php?en=omega-3+fatty+acids) and from [91] 
fatty acid, which is the precursor of prostaglandins, thromboxanes, leukotrienes, and other eicosanoids (Figure 2). These pre-inflammatory lipids have strong tumor promoting activities $[83,84]$. Inhibitors for the key enzymes cyclooxygenase-1 (COX-1) and COX-2, which convert arachidonic acid to inflammatory eicosanoids, are targets in many cancers [84-86].

Oleic acid (with 18 carbons and one double bond) is a omega-9 fatty acid and is a most common component of animal fat and vegetable oil [87]. Reports for the effect of this fatty acid in diet is contradictory. It may prevent pancreatic ductal adenocarcinoma by reducing hyperinsulinaemia and hence reducing DNA damage and tumor growth. Yet, different epidemiological studies investigating oleic acid have shown the tumor promoting activities of oleic acid [87-90]. Some of the representative roles shown for different fatty acid in cancer are shown in Figure 2.

It is well known that vitamin D3, synthesized from cholesterol (Figure 2), has anti-cancer activities, which is supported by randomized clinical trials and observational studies $[92,93]$. However, the VITAL Clinical Trials mentioned above has concluded that supplementation with vitamin $\mathrm{D}$ did not result in a lower incidence of invasive cancer or cardiovascular events than placebo (Funded by the National Institutes of Health and others; VITAL ClinicalTrials.gov number, NCT01169259) [94]. Complex mutual regulations between vitamin D and phosphate homeostasis has been suggested as one of the reasons for discrepancies in data presenting and interpretations related to vitamin $\mathrm{D}$ and cancer [95].

The off-targeting and study design issues in using lipogenesis inhibitors: In theory, all pharmacological inhibitors, although they can be highly selective, have potential off targets for their actions. In fact, as two examples, orlistat has least seven targets [28]. In addition, plasma membrane ion channels and mitochondrial electron transport complexes are identified as statin off targets [96].

Epidemiological and other studies conducted by different groups may have used significantly different methods, approaches, and/or standards. Some of these studies suffer limitations in providing valid data for correct interpretations as described by Ludwig, et al. [27]. Study designs are another major issue for preclinical and clinical studies [60]. Repurposing drugs should be carefully re-evaluated in cancer context in ways comparable to those for any novel drug [60].

Potential functional interpretations for that upregulated lipid metabolism is associated with better prognosis: Why cancer subtypes with upregulated lipid metabolism are associated with better prognosis is unclear [3] and remains to be further investigated. One speculation is that altered lipid profiles elicit immune response and such induced immune suppression. Reprogramming of cellular cholesterol metabolism has been shown to modulate the immune system $[77,97,98]$. Lipotoxicity induced cell death may be another reason. Lipotoxicity is the best studied in liver diseases [99], but it also occurs in cancer cells. For example, saturation or monounsaturation of fatty acids induced apoptotic cell death in liver cancer cells [100]. More functional, multidisciplinary, and integrated studies are necessary to address these issues.

\section{Conclusion}

Targeting metabolic reprograming in cancer is an exciting and promising area in cancer research. However, conclusive data to translate current epidemiological findings to clinical practice is lacking and requires further multidisciplinary prospective research to advance the field. Progression in the FASN-and/or cholesterol-targeted molecules has been rather slow and challenging. Highly controversial data in targeting synthesis of these lipids in cancer are presented in this review, with potential interpretations and perspectives.

The Pan-Cancer Atlas analyses [1-3] provide a uniquely comprehensive, in-depth, and interconnected understanding of biology and the complex signaling pathways in cancers [100]. Regardless of underlying reasons and mechanisms, the observations that upregulated lipid metabolism is associated with better prognosis [3] or downregulated lipid metabolism is associated with more aggressive tumor development as we have shown recently [13] suggest a more complex relationship between metabolic reprogramming and cancer progression than usually assumed. Hence, much greater efforts are need in the area of nutrition research, in metabolic reprograming, and in lipid metabolism in particular. Development in technologies in recent dacades to collect large scale "omics" data and their analyses has clearly provide new opportunities for the research in these areas.

The tumor microenvironmental $v s$. cancer cell effects and different physiological/pathological features of attached $v s$. floating cells warrant special attention. More specific targeting host cells/tissues or cancer cells should be considered. How to target specific lipid species represents another scientific and technical challenge. Improved study design for epidemiolgial and clinical trials with high and more consistent standards are pivotal to provide critical information on cancer prevention, detection, prognosis, and treatment, pertinent to lipid metabolism.

\section{Funding}

This work is supported in part by the Mary Fendrich-Hulman Charitable Trust Fund to Y.X.

\section{Acknowledgments}

Y.X. would like to thank Kevin McClelland for editing the manuscript.

\section{References}

1. Garraway LA, Lander ES (2013) Lessons from the cancer genome. Cell 153: 17-37. [Crossref]

2. Vogelstein B, Papadopoulos N, Velculescu VE, Zhou S, Diaz LA Jr, et al. (2013) Cancer genome landscapes. Science 339: 1546-1558. [Crossref]

3. Peng X, Chen Z, Farshidfar F, Xu X, Lorenzi PL, et al. (2018) Molecular Characterization and Clinical Relevance of Metabolic Expression Subtypes in Human Cancers. Cell Rep 23: 255-269. [Crossref]

4. Sanchez-Vega F, Mina M, Armenia J, Chatila WK, Luna A, et al. (2018) Oncogenic Signaling Pathways in The Cancer Genome Atlas. Cell 173: 321-337. [Crossref]

5. Hanahan D, Weinberg RA (2011) Hallmarks of cancer: the next generation. Cell 144 646-674. [Crossref]

6. Warburg O, Wind F, Negelein E (1927) The Metabolism of Tumors in the Body. J Gen Physiol 8: 519-530. [Crossref]

7. Weinhouse S, Allen A, Millington RH (1953) Metabolism of neoplastic tissue. V. Fatty acid oxidation in slices of transplanted tumors. Cancer Res 13: 367-371. [Crossref]

8. Scatena R, Bottoni P, Pontoglio A, Giardina B (2010) Revisiting the Warburg effect in cancer cells with proteomics. The emergence of new approaches to diagnosis, prognosis and therapy. Proteomics Clin Appl 4: 143-158. [Crossref]

9. Mentis AF, Kararizou E (2010) Metabolism and cancer: an up-to-date review of a mutual connection. Asian Pac J Cancer Prev 11: 1437-1444. [Crossref]

10. Hoffmann P, Roumeguère T, Schulman C, Van Velthoven R (2006) Use of statins and outcome of BCG treatment for bladder cancer. $N$ Engl J Med 355: 2705-2707. [Crossref] 
11. Van Wyhe RD, Rahal OM, Woodward WA (2017) Effect of statins on breast cancer recurrence and mortality: a review. Breast Cancer 9: 559-565. [Crossref]

12. Beckwitt CH, Brufsky A, Oltvai ZN, Wells A (2018) Statin drugs to reduce breast cancer recurrence and mortality. Breast Cancer Res 20: 144. [Crossref]

13. Cai Q, Fan Q, Buechlein A, Miller D, Nephew KP, et al. (2018) Changes in mRNA protein expression and signaling pathways in in vivo passaged mouse ovarian cancer cells. PLoS One 13: e197404. [Crossref]

14. Min HY, Lee HY (2018) Oncogene-Driven Metabolic Alterations in Cancer. Biomol Ther (Seoul) 26: 45-56. [Crossref]

15. Ray U, Roy SS (2018) Aberrant lipid metabolism in cancer cells - the role of oncolipidactivated signaling. FEBS J 285: 432-443. [Crossref]

16. Tania M, Khan MA, Song Y (2010) Association of lipid metabolism with ovarian cancer. Curr Oncol 17: 6-11. [Crossref]

17. Xie W, Ning L, Huang Y, Liu Y, Zhang W, et al. (2017) Statin use and survival outcomes in endocrine-related gynecologic cancers: A systematic review and meta-analysis. Oncotarget 8: 41508-41517. [Crossref]

18. Sunami Y, Rebelo A, Kleeff J (2017) Lipid Metabolism and Lipid Droplets in Pancreatic Cancer and Stellate Cells. Cancers (Basel) 10: 3-5. [Crossref]

19. Buckley D, Duke G, Heuer TS, O'Farrell M, Wagman AS, et al. (2017) Fatty acid synthase - Modern tumor cell biology insights into a classical oncology target. Pharmacol Ther 177: 23-31. [Crossref]

20. Lauby-Secretan B (2019) Obesity and Cancer. Bull Cancer.

21. Godos J, Tieri M, Ghelfi F, Titta L, Marventano S, et al. (2019) Dairy foods and health: an umbrella review of observational studies. Int J Food Sci Nutr 14: 1-14. [Crossref]

22. Sadeghi A, Shab-Bidar S, Parohan M, Djafarian K (2019) Dietary Fat Intake and Risk of Ovarian Cancer: A Systematic Review and Dose-Response Meta-Analysis of Observational Studies. Nutr Cancer 71: 939-953. [Crossref]

23. Zhang F, Du G (2012) Dysregulated lipid metabolism in cancer. World J Biol Chem 3: 167-174. [Crossref]

24. Garg SK, Maurer H, Reed K, Selagamsetty R (2014) Diabetes and cancer: two diseases with obesity as a common risk factor. Diabetes Obes Metab 16: 97-110. [Crossref]

25. Luo L, Liu M (2016) Adipose tissue in control of metabolism. J Endocrinol 231: R77-R99. [Crossref]

26. Ding X, Zhang W, Li S, Yang H (2019) The role of cholesterol metabolism in cancer Am J Cancer Res 9: 219-227. [Crossref]

27. Ludwig DS, Willett WC, Volek JS, Neuhouser ML (2018) Dietary fat: From foe to friend? Science 362: 764-770. [Crossref]

28. Schcolnik-Cabrera A, Chávez-Blanco A, Domínguez-Gómez G, Taja-Chayeb L, Morales-Barcenas R, et al. (2018) Orlistat as a FASN inhibitor and multitargeted agent for cancer therapy. Expert Opin Investig Drugs 27: 475-489. [Crossref]

29. Wu X, Qin L, Fako V, Zhang JT (2014) Molecular mechanisms of fatty acid synthase (FASN)-mediated resistance to anti-cancer treatments. Adv Biol Regul 54: 214-221. [Crossref]

30. Bauerschlag DO, Maass N, Leonhardt P, Verburg FA, Pecks U, et al. (2015) Fatty acid synthase overexpression: target for therapy and reversal of chemoresistance in ovarian cancer. J Transl Med 13: 146. [Crossref]

31. Rao KN (1995) The significance of the cholesterol biosynthetic pathway in cell growth and carcinogenesis (review). Anticancer Res 15: 309-314. [Crossref]

32. Chimento A, Casaburi I, Avena P, Trotta F, De Luca A, et al. (2018) Cholesterol and Its Metabolites in Tumor Growth: Therapeutic Potential of Statins in Cancer Treatment. Front Endocrinol (Lausanne) 9: 807. [Crossref]

33. Cao D, Song X, Che L, Li X, Pilo MG, et al. (2017) Both de novo synthetized, and exogenous fatty acids support the growth of hepatocellular carcinoma cells. Liver Int 37: 80-89. [Crossref]

34. Che L, Pilo MG, Cigliano A, Latte G, Simile MM, et al. (2017) Oncogene dependent requirement of fatty acid synthase in hepatocellular carcinoma. Cell Cycle 16: 499-507. [Crossref]

35. Bruning U, Morales-Rodriguez F, Kalucka J, Goveia J, Taverna F, et al. (2018) Impairment of Angiogenesis by Fatty Acid Synthase Inhibition Involves mTOR Malonylation. Cell Metab 28: 866-880. [Crossref]
36. Jiang L, Wang H, Li J, Fang X, Pan H, et al. (2014) Up-regulated FASN expression promotes transcoelomic metastasis of ovarian cancer cell through epithelialmesenchymal transition. Int J Mol Sci 15: 11539-11554. [Crossref]

37. Kridel SJ, Lowther WT, Pemble CW (2007) Fatty acid synthase inhibitors: new directions for oncology. Expert Opin Investig Drugs 16: 1817-1829. [Crossref]

38. Fritz G (2005) HMG-CoA reductase inhibitors (statins) as anticancer drugs (review) Int J Oncol 27: 1401-1409. [Crossref]

39. Mullen GE, Yet L (2015) Progress in the development of fatty acid synthase inhibitors as anticancer targets. Bioorg Med Chem Lett 25: 4363-4369. [Crossref]

40. Tomek K, Wagner R, Varga F, Singer CF, Karlic H, et al. (2011) Blockade of fatty acid synthase induces ubiquitination and degradation of phosphoinositide-3-kinase signaling proteins in ovarian cancer. Mol Cancer Res 9: 1767-1779. [Crossref]

41. Huang HQ, Tang J, Zhou ST, Yi T, Peng HL, et al. (2012) Orlistat, a novel poten antitumor agent for ovarian cancer: proteomic analysis of ovarian cancer cells treated with Orlistat. Int J Oncol 41: 523-532. [Crossref]

42. Papaevangelou E, Almeida GS, Box C, deSouza NM, Chung YL, et al. (2018) The effect of FASN inhibition on the growth and metabolism of a cisplatin-resistant ovarian carcinoma model. Int $J$ Cancer 143: 992-1002. [Crossref]

43. Matusewicz L, Meissner J, Toporkiewicz M, Sikorski AF (2015) The effect of statins on cancer cells--review. Tumour Biol 36: 4889-4904. [Crossref]

44. Li YR, Ro V, Steel L, Carrigan E, Nguyen J (2019) Impact of long-term lipid-lowering therapy on clinical outcomes in breast cancer. Breast Cancer Res Treat 176: 669-677. [Crossref]

45. Omori M, Okuma Y, Hakozaki T, Hosomi Y (2019) Statins improve survival in patient previously treated with nivolumab for advanced non-small cell lung cancer: An observational study. Mol Clin Oncol 10: 137-143. [Crossref]

46. Nevadunsky NS, Van Arsdale A, Strickler HD, Spoozak LA, Moadel A, et al. (2015) Association Between Statin Use and Endometrial Cancer Survival. Obstet Gynecol 126: 144-150. [Crossref]

47. Mace AG, Gantt GA, Skacel M, Pai R, Hammel JP, et al. (2013) Statin therapy is associated with improved pathologic response to neoadjuvant chemoradiation in recta cancer. Dis Colon Rectum 56: 1217-1227. [Crossref]

48. Gaist D, Andersen L, Hallas J, Sørensen HT, Schrøder HD, et al. (2013) Use of statins and risk of glioma: a nationwide case-control study in Denmark. Br J Cancer 108: 715-720. [Crossref]

49. Sleijfer S, Van der Gaast A, Planting AS, Stoter G, Verweij J, et al. (2005) The potential of statins as part of anti-cancer treatment. Eur J Cancer 41: 516-522. [Crossref]

50. Zhou P, Li B, Liu B, Chen T, Xiao J, et al. (2018) Prognostic role of serum tota cholesterol and high-density lipoprotein cholesterol in cancer survivors: A systematic review and meta-analysis. Clin Chim Acta 477: 94-104. [Crossref]

51. Hao B, Bi B, Sang C, Yu M, Di D, et al. (2019) Systematic Review and Meta-Analysi of the Prognostic Value of Serum High-Density Lipoprotein Cholesterol Levels for Solid Tumors. Nutr Cancer 71: 547-556. [Crossref]

52. Guan X, Liu Z, Zhao Z, Zhang X, Tao, et al. (2019) Emerging roles of low-density lipoprotein in the development and treatment of breast cancer. Lipids Health Dis 18 137. [Crossref]

53. Cedó L, Reddy ST, Mato E, Blanco-Vaca F, Escolà-Gil JC, et al. (2019) HDL and LDL Potential New Players in Breast Cancer Development. J Clin Med 8: E853. [Crossref]

54. Guo F, Hong W, Yang M, Xu D, Bai Q, et al. (2018) Upregulation of 24(R/S),25epoxycholesterol and 27-hydroxycholesterol suppresses the proliferation and migration of gastric cancer cells. Biochem Biophys Res Commun 504: 892-898. [Crossref]

55. Pirmoradi L, Seyfizadeh N, Ghavami S, Zeki AA, Shojaei S, et al. (2019) Targeting cholesterol metabolism in glioblastoma: a new therapeutic approach in cancer therapy. J Investig Med 67: 715-719. [Crossref]

56. Braicu EI, Darb-Esfahani S, Schmitt WD, Koistinen KM, Heiskanen L, et al. (2017) High-grade ovarian serous carcinoma patients exhibit profound alterations in lipid metabolism. Oncotarget 8: 102912-102922. [Crossref]

57. Petan T, Jarc E, Jusović M (2018) Lipid Droplets in Cancer: Guardians of Fat in Stressful World. Molecules 23: E1941. [Crossref]

58. Cattarino S, Seisen T, Drouin SJ, Renard-Penna R, Leon P, et al. (2015) Influence of statin use on clinicopathological characteristics of localized prostate cancer and outcomes obtained after radical prostatectomy: a single center study. Can J Urol 22: 7703-7708. [Crossref] 
59. Ishak-Howard MB, Okoth LA, Cooney KA (2014) Statin use and the risk of recurrence after radical prostatectomy in a cohort of men with inherited and/or early-onset forms of prostate cancer. Urology 83: 1356-1361. [Crossref]

60. Abdullah MI, De Wolf E, Jawad MJ, Richardson A (2018) The poor design of clinical trials of statins in oncology may explain their failure - Lessons for drug repurposing. Cancer Treat Rev 69: 84-89. [Crossref]

61. Farooqi MAM, Malhotra N, Mukherjee SD, Sanger S, Dhesy-Thind SK, et al. (2018) Statin therapy in the treatment of active cancer: A systematic review and meta-analysis of randomized controlled trials. PLoS One 13: e0209486. [Crossref]

62. Ventura R, Mordec K, Waszczuk J, Wang Z, Lai J, et al. (2015) Inhibition of de novo Palmitate Synthesis by Fatty Acid Synthase Induces Apoptosis in Tumor Cells by Remodeling Cell Membranes, Inhibiting Signaling Pathways, and Reprogramming Gene Expression. EBioMedicine 2: 808-824. [Crossref]

63. Min HY, Lee HY (2018) Oncogene-Driven Metabolic Alterations in Cancer. Biomol Ther (Seoul) 26: 45-56. [Crossref]

64. Cai Q, Xu Y (2015) The microenvironment reprograms circuits in tumor cells. Mol Cell Oncol 2: e969634. [Crossref]

65. Cai Q, Yan L, Xu Y (2015) Anoikis resistance is a critical feature of highly aggressive ovarian cancer cells. Oncogene 34: 3315-3324. [Crossref]

66. Roby KF, Taylor CC, Sweetwood JP, Cheng Y, Pace JL, et al. (2000) Development of a syngeneic mouse model for events related to ovarian cancer. Carcinogenesis 21 : 585-591. [Crossref]

67. Greenaway J, Moorehead R, Shaw P, Petrik J (2008) Epithelial-stromal interaction increases cell proliferation, survival and tumorigenicity in a mouse model of human epithelial ovarian cancer. Gynecol Oncol 108: 385-394. [Crossref]

68. Cai H, Xu Y (2013) The role of LPA and YAP signaling in long-term migration of human ovarian cancer cells. Cell Commun Signal 11: 31. [Crossref]

69. Zhang P, Zhou H, Lu K, Wang Y, Feng T, et al. (2019) Circulating tumor cells in the clinical cancer diagnosis. Clin Transl Oncol. [Crossref]

70. Zhang X, Ju S, Wang X, Cong H (2019) Advances in liquid biopsy using circulating tumor cells and circulating cell-free tumor DNA for detection and monitoring of breast cancer. Clin Exp Med 19: 271-279. [Crossref]

71. Kipps E, Tan DS, Kaye SB (2013) Meeting the challenge of ascites in ovarian cancer: new avenues for therapy and research. Nat Rev Cancer 13: 273-282. [Crossref]

72. Smolle E, Taucher V, Haybaeck J (2014) Malignant ascites in ovarian cancer and the role of targeted therapeutics. Anticancer Res 34: 1553-1561. [Crossref]

73. Xia X, Li F, He J, Aji R, Gao D, et al. (2019) Organoid technology in cancer precision medicine. Cancer Lett 457: 20-27. [Crossref]

74. McKay DJ, Stutzman AV, Dowen JM (2019) Advancements in mapping 3D genome architecture. Methods [Crossref]

75. Zhao Z, Cai Q, Xu Y (2016) The Lipidomic Analyses in Low and Highly Aggressive Ovarian Cancer Cell Lines. Lipids 51: 179-187. [Crossref]

76. Greenaway JB, Virtanen C, Osz K, Revay T, Hardy D, et al. (2016) Ovarian tumour growth is characterized by mevalonate pathway gene signature in an orthotopic, syngeneic model of epithelial ovarian cancer. Oncotarget 7: 47343-47365. [Crossref]

77. Wang Y, Sun XQ, Lin HC, Wang DS, Wang ZQ, et al. (2019) Correlation between immune signature and high-density lipoprotein cholesterol level in stage II/III colorectal cancer. Cancer Med 8: 1209-1217. [Crossref]

78. Sala-Vila A, Calder PC (2011) Update on the relationship of fish intake with prostate, breast, and colorectal cancers. Crit Rev Food Sci Nutr 51: 855-871. [Crossref]

79. MacLean CH, Newberry SJ, Mojica WA, Khanna P, Issa AM, et al. (2006) Effects of omega-3 fatty acids on cancer risk: a systematic review. JAMA 295: 403-415. [Crossref]
80. Grey A, Bolland M (2014) Clinical trial evidence and use of fish oil supplements. JAMA Intern Med 174: 460-462. [Crossref]

81. Manson JE, Cook NR, Lee IM, Christen W, Bassuk SS, et al. (2019) Marine n-3 Fatty Acids and Prevention of Cardiovascular Disease and Cancer. N Engl J Med 380: 23-32. [Crossref]

82. Di Pasquale MG (2009) The essentials of essential fatty acids. J Diet Suppl 6: 143-161. [Crossref]

83. Gomes RN, Felipe da Costa S, Colquhoun A (2018) Eicosanoids and cancer. Clinics (Sao Paulo) 73: e530s. [Crossref]

84. Haeggstrom JZ (2018) Leukotriene biosynthetic enzymes as therapeutic targets. J Clin Invest 128: 2680-2690. [Crossref]

85. Pannunzio A, Coluccia M (2018) Cyclooxygenase-1 (COX-1) and COX-1 Inhibitors in Cancer: A Review of Oncology and Medicinal Chemistry Literature. Pharmaceuticals (Basel) 11: E101. [Crossref]

86. Consalvi S, Biava M, Poce G (2015) COX inhibitors: a patent review (2011 - 2014) Expert Opin Ther Pat 25: 1357-1371. [Crossref]

87. Banim PJ, Luben R, Khaw KT, Hart AR (2018) Dietary oleic acid is inversely associated with pancreatic cancer - Data from food diaries in a cohort study. Pancreatology 18: 655-660. [Crossref]

88. Yang P, Su C, Luo X, Zeng H, Zhao L, et al. (2018) Dietary oleic acid-induced CD36 promotes cervical cancer cell growth and metastasis via up-regulation Src/ERK pathway. Cancer Lett 438: 76-85. [Crossref]

89. Liotti A, Cosimato V, Mirra P, Calì G, Conza D, et al. (2018) Oleic acid promotes prostate cancer malignant phenotype via the $\mathrm{G}$ protein-coupled receptor FFA1/GPR40. J Cell Physiol 233: 7367-7378. [Crossref]

90. Marcial-Medina C, Ordoñez-Moreno A, Reyes-Gonzales C, Cortes-Reynosa P, Perez Salazar E, et al. (2019) Oleic acid induces migration through a FFAR1/4, EGFR and Akt-dependent pathway in breast cancer cells. Endocr Connect. [Crossref]

91. Grant WB, Moukayed M (2019) Vitamin D3 from Ultraviolet-B Exposure or Oral Intake in Relation to Cancer Incidence and Mortality. Curr Nutr Rep 8: 203-211. [Crossref]

92. Wu X, Hu W, Lu L, Zhao Y, Zhou Y4, et al. (2019) Repurposing vitamin D for treatment of human malignancies via targeting tumor microenvironment. Acta Pharm $\operatorname{Sin} B$ 9: 203-219. [Crossref]

93. Manson JE, Cook NR, Lee IM, Christen W, Bassuk SS, et al. (2019) Vitamin D Supplements and Prevention of Cancer and Cardiovascular Disease. $N$ Engl J Med 380: 33-44. [Crossref]

94. Brown RB (2019) Vitamin D, cancer, and dysregulated phosphate metabolism. Endocrine 65: 238-243. [Crossref]

95. Curry L, Almukhtar H, Alahmed J, Roberts R, Smith PA, et al. (2019) Simvastatin Inhibits L-Type Ca2+-Channel Activity Through Impairment of Mitochondrial Function. Toxicol Sci 169: 543-552.

96. Yvan-Charvet L, Bonacina F, Guinamard RR, Norata GD (2019) Immunometabolic function of cholesterol in cardiovascular disease and beyond. Cardiovasc Res 115: 1393-1407. [Crossref]

97. Shahoei SH, Nelson ER (2019) Nuclear receptors, cholesterol homeostasis and the immune system. J Steroid Biochem Mol Biol 191: 105364. [Crossref]

98. Trauner M, Arrese M, Wagner M (2010) Fatty liver and lipotoxicity. Biochim Biophys Acta 1801: 299-310. [Crossref]

99. Shih LM, Tang HY, Lynn KS, Huang CY, Ho HY, et al. (2018) Stable Isotope-Labeled Lipidomics to Unravel the Heterogeneous Development Lipotoxicity. Molecules 23: E2862. [Crossref]

100. Hidaka BH, Li S, Harvey KE, Carlson SE, Sullivan DK, et al. (2015) Omega-3 and omega-6 Fatty acids in blood and breast tissue of high-risk women and association with atypical cytomorphology. Cancer Prev Res (Phila) 8: 359-364. [Crossref]

Copyright: $(02019 \mathrm{Xu}$ Y. This is an open-access article distributed under the terms of the Creative Commons Attribution License, which permits unrestricted use, distribution, and reproduction in any medium, provided the original author and source are credited. 